\title{
STRATEGI PENGELOLAAN WISATA PANTAI BERBASIS KESESUAIAN DAN DAYA DUKUNG DI KAMPUNG PENYU KABUPATEN KEPULAUAN SELAYAR
}

\author{
(Beach Tourism Management Strategy Based Suitability and \\ Carrying Capacity In Kampung Penyu \\ Selayar Islands Regency) \\ Nurul Ulfa Haerani 1), Muhammad Kasnir ${ }^{2)}$ dan Asbar ${ }^{3)}$ \\ 1) Mahasiswa Pascasarjana Univeritas Muslim Indonesia Makassar \\ 2) Program Studi Budidaya Perairan FPIK UMI Makassar \\ 3) Progarm Studi Ilmu Kelautan FPIK UMI Makassar \\ Korespondensi:upphashine@gmail.com
}

Diterima: tanggal 1 Juli 2019; Disetujui 15 Oktober 2019

\begin{abstract}
Beach tourism is one of the favorite attractions of the community, especially in Indonesia. Aside from being cheap, Indonesia's $70 \%$ natural condition is the oceans and coastal areas that make coastal tourism appear a lot. The tourism object of the Turtle Village is located in the Tulang Village of Barugaiya District in Selayar Island Regency. From the results of research and data processing on the Analysis of Potential Kampung Penyu areas for coastal tourism areas by conducting direct observations and quantitative descriptive methods through scoring that is high potential. For Conformity Value of Coastal Tourism by looking at a number of variables from 3 location points, the results show that the area is very suitable for coastal tourism activities. For carrying capacity or carrying capacity, location 1 can accommodate around 889 people / day for coastal tourism activities, location 2 can accommodate 816 people / day for beach tourism activities and location 3 can accommodate 351 people / day for beach tourism activities. By looking at the potential, suitability and carrying capacity, a Regional Development Strategy can be formulated, namely the need to socialize to the community the community's readiness to develop areas other than coastal tourism areas but also ecotourism and culture. This can be done using the Focus Group Discussion (FGD) between communities and StakeHolder to find obstacles, and problems that hinder the development and development of tourism areas generally in Bontomanai Sub-District and especially in Kampung Penyu Areas.
\end{abstract}

Keywords: Beach Tourism, Tourism Potential, Suitability of Beach Tourism, Tourism Carrying Capacity

\begin{abstract}
ABSTRAK
Wisata pantai merupakan salahsatu wisata favorit masyarakat, khususnya di Indonesia. Selain murah, kondisi alam Indonesia yang $70 \%$ adalah lautan dan kawasan pesisir membuat wisata pantai banyak bermunculan. Objek wisata Kampung Penyu yang terletak di Dusun Tulang Desa Desa Barugaiya Kabupaten Kepulauan. Dari hasil penelitian dan pengolahan data mengenai Analisis Potensi Kawasan kampung Penyu untuk kawasan wisata pantai dengan melakukan pengamatan langsung dan dengan metode deskriptif kuantitatif melalui skoring yaitu potensial tinggi. Untuk Nilai Kesesuaian Wisata Pantai dengan melihat beberapa variabel dari 3 titik lokasi memberikan hasil bahwa kawasan sangat sesuai dikembangkan untuk kegiatan wisata pantai. Untuk daya dukung wisata atau Carryng Capacity, lokasi 1 dapat menampung sekitar menampung 889 orang/hari untuk kegiatan wisata pantai, lokasi 2 dapat menampung 816 orang/hari untuk kegiatan wisata pantai dan lokasi 3 dapat menampung 351 orang/hari untuk kegiatan wisata pantai. Dengan melihat potensi, keseuaian dan daya dukung, maka dapat dirumuskan Strategi Pengembangan Kawasan yaitu perlu dilakukan sosialisasi kepada masyarakat akan kesiapan masyarakat untuk mengembangkan kawasan selain kawasan wisata
\end{abstract}


pantai melainkan juga ekowisata dan budaya hal ini dapat dilakukan dengan metode FGD (Focus Group Discussion) antara masyarakat dan para Stakeholder guna menemukan hambatan, serta maslah yang menghambat pembangungan dan pengembangan kawasan wisata umumnya di Kecamatan Bontomanai dan Khususnya di Kawasan Kampung Penyu.

Kata kunci: Wisata Pantai, Potensi Wisata, Kesesuaian Wisata Pantai, Daya Dukung Wisata

\section{PENDAHULUAN}

Pantai adalah salah satu tujuan berwisata atau berlibur yang favorit. Selain kita bisa menikmati sunrise dan sunset, kita juga bisa berenang atau bahkan melakukan olahraga air lainnya seperti snorkeling, diving dan sebagainya. Untuk alasan kesehatan, air laut yang asin itu mempunyai khasiat yang dapat menyembuhkan penyakit tertentu, seperti gatal-gatal.

Objek wisata Kampung Penyu yang terletak di Dusun Tulang Desa Desa Barugaiya Kabupaten Kepulauan Selayar merupakan Salah Satu Objek Wisata Berbasis Ekowisata di Kabupaten Kepulauan Selayar. Lokasi yaang Relatif dapat dijangkau oleh wisatawan sekitar $\pm 40 \mathrm{Km}$ dari Pelabuhan Penyeberangan Pamatata atau sekitar $12 \mathrm{Km}$ dari Kota Benteng Kabupaten Kepulauan Selayar membuat kampung penyu menjadi salah satu destinasi wisata yang wajib di kunjungi oleh para wisatawan baik wistawan domestik maupun luar negeri. Dalam Rencana Induk Pariwisata Kabupaten
Selayar Tahun

2017-2022

(RIPARDDA), Kecamatan Bontomanai merupakan kawasan pengembangan Pariwisata Zona I yang meliputi pengembangan wisata pantai, wisata budaya, pesisir. Sejalan dengan Rencana Tata Ruang Wilayah (RTRW) Kabupaten Selayar tahun 2017-2022 yang arahan pengembangan kawasan pesisir sebagai arahan pengembangan wisata pantai dan wisata bahari. Dengan adanya aturan dan arahan perencanaan maka tujuan penelitian ini adalah melakukan kajian penelitian strategi pengelolaan wisata pantai berbasis kesesuaian dan daya dukung di kampung penyu Kabupaten Kepulauan Selayar. Kegunaannya adalah sebagai bahan pertimbangan bagi pemerintah dalam melihat potensi suatu kawasan untuk dikembangkan sebagai destinasi wisata yang berdampak terhadap perkembangan kawasan dan memberi nilai tambah bagi Pendapatan Daerah dan peningkatan pendapatan bagi masyarakat sekitar apabila kawasan tersebut dikembangkan. 
MATERI DAN METODE

Kegiatan Penelitian ini dilakukan pada tanggal 30 September - 30
November 2018 dan kegiatan ini dilaksanakan di Dusun Tulang, Desa Barugaiya, Kecamatan Bontomanai, Kabupaten Kepulauan Selayar.

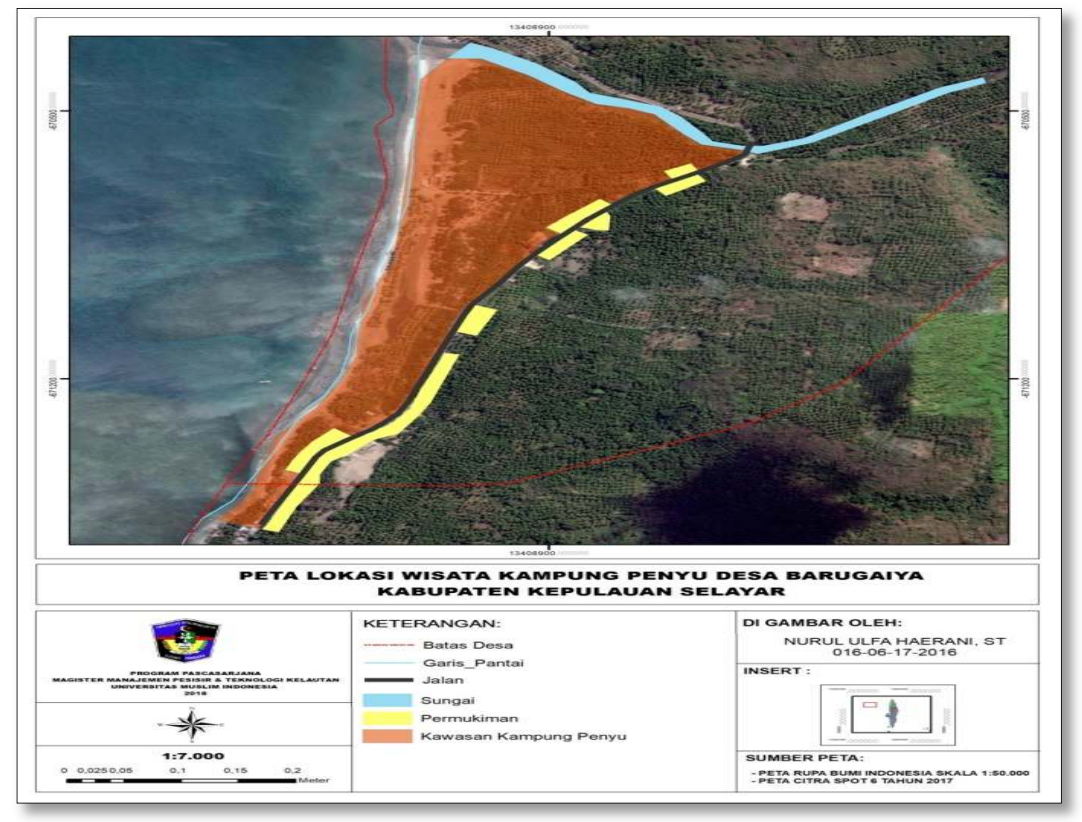

Gambar 1. Peta lokasi penelitian

Alat dan bahan yang digunakan dalam penelitian ini yaitu GPS, Kamera digital, alat tulis menulis, rol meter, formulir kusioner, Laptop , citra Spot 2018 dan peta RBI bakosurtanal 2010.

Penelitian ini jenis datanya terdiri dari data primer dan data sekunder. Merupakan data yang bernilai bukan angka. Data kualitatif dalam penelitian ini adalah Rencana Tata Ruang Wilayah Kabupaten Kepulauan Selayar dan Rencana Induk Perencanaan Wisata Daerah (RIPDA). Data kuantitatif berupa data daya tarik objek wisata, kondisi alam, aksesbilitas, sarana kegiatan wisata, sarana pelengkap wisata, peta citra, data sebaran objek wisata. data kuantitatif diambil melalui obeservasi lapangan, pengamatan langsung dan wawancara.

Sesuai dengan jenis data yang diperlukan dalam penelitian ini, maka peneliti menggunakan teknik pengumpulan data sebagai berikut: 1) Observasi Lapangan; 2) Wawancara; 3) Studi Dokumentasi.

Sesuai tujuan dari penelitian ini, untuk mengetahui potensi wisata pantai di Kampung Penyu Kabupaten Kepulauan Selayar digunakan teknik 
analisis Kesesuaian Wisata (IKW), Daya

Dukung Kawasan (DDK) dan Sistem Informasi Geografis, teknik skoring dan klasifikasi, selanjutnya untuk mengetahui usaha pengembangan objek wisata pantai kampong penyu digunakan teknik analisis SWOT (Threats, Opportunities, Weaknesses \& Strengths). Analisis data tersebut dimulai dengan tahapan sebagai berikut:

1. Analisis Potensi Objek Wisata

\section{Pantai Kampung Penyu}

Dalam menentukan potensi objek wisata, perlu dilakukan klasifikasi. Analisis klasifikasi digunakan untuk menentukan kelas potensi objek wisata.. Analisis klasifikasi ini dimulai dengan tahapan sebagai berikut: 1) Pemilihan indikator penelitian; 2) Skoring. Kriteria dan asumsi yang digunakan dalam penskoran tiap-tiap variable adalah sebagai berikut: Variabel Daya Tarik Objek Wisata; Variabel Kondisi Alam; Variabel Aksesbiltas Wisata; Sarana Pokok Kegiatan Wisata dan Sarana Pelengkap Kegiatan Wisata.

$$
\text { Pengklasifikasian dilakukan }
$$

berdasarkan total skor variable penelitian, baik potensi internal maupun eksternal. Dengan menggunakan rumus interval kelas Interval kelas potensi objek wisata dari perhitungan di atas dapat dikeahui pembagian kelasa adalah sebagai berikut:

Tabel 1. Pembagian Kelas Potensi Objek Wisata.

\begin{tabular}{|c|c|c|c|}
\hline No & Jumlah & $\begin{array}{c}\text { Pembagian Kelas } \\
\text { Potensial }\end{array}$ & Keterangan \\
\hline 1 & $511-401$ & Potensial Tinggi & $\begin{array}{l}\text { Sebagian besar karakteristik objek } \\
\text { wisata Pantai Kampung Penyu } \\
\text { merupakan faktor pendorong } \\
\text { pengembangan objek wisata }\end{array}$ \\
\hline 2 & $400-290$ & Potensial Sedang & $\begin{array}{l}\text { Karakteristik objek wisata Pantai } \\
\text { Kampung Penyu yang menjadi faktor } \\
\text { pendorong dan penghambat adalah } \\
\text { seimbang atau sama. }\end{array}$ \\
\hline 3 & $289-179$ & Potensial Rendah & $\begin{array}{l}\text { Sebagian kecil karakteristik objek } \\
\text { wisata Pantai Kampung Penyu } \\
\text { merupakan faktor pendorong } \\
\text { pengembangan objek wisata }\end{array}$ \\
\hline
\end{tabular}

2. Analisis Kesesuaian Wisata Pantai

Analisis data menggunakan Indeks Kesesuaian Wisata (IKW) dengan matriks kesesuaian yang disusun berdasarkan kepentingan setiap parameter untuk mendukung kegiatan 
pada daerah tersebut. Rumus yang dipakai untuk kesesuaian wisata pantai adalah (Yulianda, 2007; Juliana, 2013):

\section{Analisis Daya Dukung Kawasan} Untuk Kegiatan Wisata Pantai

Analisis daya dukung ditunjukan pada pengembangan wisata pantai agar dalam pengembangannya tidak menganggu kegiatan konservasi. Metode yang digunakan adalah konsep Daya Dukung Kawasan (DDK) yaitu jumlah maksimum pengunjung yang secara fisik dapat ditampung di kawasan yang disediakan pada waktu tertentu tanpa menimbulkan gangguan pada manusia (Yulianda 2007). dengan persamaan dalam bentuk rumus:

\section{HASIL DAN PEMBAHASAN}

Desa Barugaiya yang merupakan salah satu desa yang berada dalam wilayah administratif kecamatan Bontomanai. Secara geografis desa Barugaia terletak di pesisir pantai barat pulau Selayar yang memanjang dari utara ke selatan dan diapit oleh dua buah sungai yaitu Sungai Taman Rojak dan Sungai Tulang dengan batas wilayah desa :Sebelah Utara berbatasan dengan Desa Bontolempangan, Sebelah Selatan berbatasan dengan Desa Parak, Sebelah Timur berbatasan dengan Desa Polebungin dan Desa Mare-Mare dan disebelah Sebelah Barat berbatasan dengan Laut Flores.

\section{- Analisis Potensi Objek Wisata} Pantai Kampung Penyu

Ke-empat variabel penelitian dilakukan pembobotan dan dijumlah skornya, maka dapat diketahui bahwa potensi objek wisata Pantai mempunyai nilai skor akhir 423. Berdasarkan tabel pembagian kelas potensi objek wisata di bawah ini, skor tersebut termasuk dalam kelas potensial tinggi. Kelas potensi yang dimiliki objek wisata Pantai Kampung Penyu dapat diartikan bahwa karakteristik yang ada di objek wisata Umbul Ingas yang menjadi faktor pendorong dan penghambat dalam usaha pengembangan objek wisata adalah seimbang. Hal ini berarti tidak semua karakteristik yang ada di objek wisata Pantai Kampung Penyu merupakan Sebagian besar karakteristik objek wisata Pantai Kampung Penyu merupakan faktor pendorong pengembangan objek wisata.

\section{- Analisis Indeks Kesesuaian Wisata}

Dari hasil analisis indeks kesesuaian dengan metode overlay yang 
mengambil 3 lokasi di Kawasan Kampung Penyu, Lokasi 1 memiliki posisi dekat dengan muara sungai Tulang. Hasil dari kesesuaian wisata pantai di Kawasan Kampung penyu untuk Lokasi 1 memiliki indeks kesesuaian sebesar 64,28\% yaitu Sesuai bersyarat. Hasil dari kesesuaian wisata pantai di Kawasan Kampung penyu untuk Lokasi 2 memiliki indeks kesesuaian sebesar $\mathbf{9 6 , 5 5} \%$ yaitu Sangat Sesuai. penyu/tukik.

Dan untuk lokasi 3, hasil bersyarat dengan nilai $17-<50 \%$; dan kesesuaian wisata sebesar $\mathbf{9 6}, \mathbf{4 2} \% \quad \mathrm{TS}=$ tidak sesuai dengan nilai $<17 \%$.

Tabel 2. Hasil Pengamatan dan Pembobotan Kesesuaian Wisata Pantai kategori Berenang dan Rekreasi Pantai

\begin{tabular}{|c|c|c|c|c|c|c|c|c|c|c|}
\hline \multirow{2}{*}{ Parameter $\mathbf{x}$} & \multirow{2}{*}{ Bobot } & \multicolumn{3}{|c|}{ Lokasi 1} & \multicolumn{3}{|c|}{ Lokasi 2} & \multicolumn{3}{|c|}{ Lokasi 3} \\
\hline & & $\begin{array}{c}\text { Hasil } \\
\text { Pengamatan }\end{array}$ & Kategori & Skor & $\begin{array}{c}\text { Hasil } \\
\text { Pengamatan }\end{array}$ & Kategori & Skor & $\begin{array}{c}\text { Hasil } \\
\text { Pengamatan }\end{array}$ & Kategori & Skor \\
\hline $\begin{array}{l}\text { Tipe Pantai/Jenis } \\
\text { Pantai }\end{array}$ & 5 & Pasir putih & S1 & 3 & Pasir putih & S1 & 3 & Pasir putih & S1 & 3 \\
\hline Lebar Pantai (m) & 5 & $34 \mathrm{~m}$ & S1 & 3 & $32 \mathrm{~m}$ & S1 & 3 & $14 \mathrm{~m}$ & S3 & 1 \\
\hline $\begin{array}{l}\text { Kedalaman Perairan } \\
(\mathrm{m})\end{array}$ & 5 & $2-4 \mathrm{~m}$ & S3 & 1 & $3 \mathrm{~m}$ & S1 & 3 & $3 \mathrm{~m}$ & S1 & 3 \\
\hline Material Dasar Pantai & 3 & Pasir Berlumpur & S1 & 1 & Pasir & S1 & 3 & Pasir & S1 & 3 \\
\hline Kecapatan Arus (m/d) & 3 & $0.072 \mathrm{~m} / \mathrm{d}$ & S1 & 1 & 0.066 & S1 & 3 & 0,075 & S1 & 3 \\
\hline Kemiringan Pantai (\%) & 3 & $7,18^{\circ}$ & S2 & 2 & $7,18^{\circ}$ & S1 & 3 & $7,18^{\circ}$ & S1 & 3 \\
\hline $\begin{array}{l}\text { Kecerahan Perairan } \\
(\mathrm{m})\end{array}$ & 1 & $4 \mathrm{~m}$ & S3 & 1 & $6 \mathrm{~m}$ & S2 & 2 & $7-8 \mathrm{~m}$ & S2 & 2 \\
\hline $\begin{array}{l}\text { Penutupan Lahan } \\
\text { Pantai }\end{array}$ & 1 & lahan terbuka & S1 & 3 & Pohon Kelapa & S1 & 3 & Pohon kelapa & S1 & 3 \\
\hline $\begin{array}{l}\text { Biota } \\
\text { Berbahaya/Dilindungi }\end{array}$ & 1 & Penyu & S2 & 2 & Tidak Ada & S1 & 3 & Tidak Ada & S1 & 3 \\
\hline \multirow[t]{2}{*}{$\begin{array}{l}\text { Ketersediaan Air } \\
\text { Tawar (Jarak/km) }\end{array}$} & 1 & $\pm 0,02 \pm$ & S1 & 1 & $\pm 0,01$ & S1 & 3 & $\pm 0,07$ & S1 & 3 \\
\hline & 28 & & & 18 & & & 29 & & & 27 \\
\hline \multicolumn{2}{|c|}{$\begin{array}{c}\text { Indeks Kesesuaian Wisata } \\
\text { Pantai \% }\end{array}$} & \multicolumn{3}{|c|}{64,28} & \multicolumn{3}{|c|}{96,55} & \multicolumn{3}{|c|}{96,42} \\
\hline
\end{tabular}




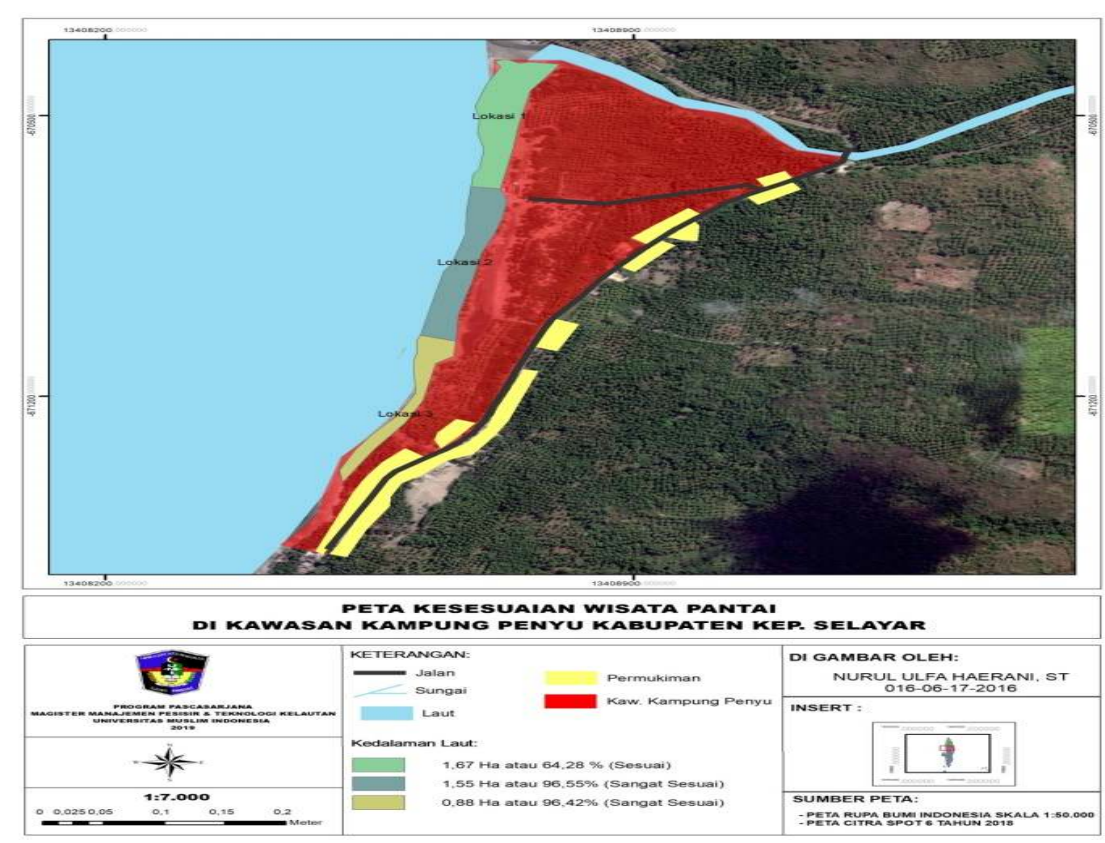

Gambar 3. Peta Kesesuaian Wisata Pantai

- Metode Analisis Daya Dukung Kawasan Wisata (DDK) untuk Kegiatan Wisata Pantai

Analisis Daya Dukung Kawasan bertujuan untuk mengetahui jumlah maksimum pengunjung yang dapat ditampung di kawasan tertentu tanpa menimbulkan pengaruh negatif pada lingkungan dan manusia. Analisis Daya Dukung mengacu kepada Yulianda
(2007) dan Juliana (2013). untuk menghitung analisis daya dukung wisata, maka dalam penelitian ini mengambil 3 lokasi dengan luasan lokasi yang berbeda-beda sesuai karakeristik wilayahnya. Hasil analisis daya dukung kegiatan wisata pantai di kawasan kampung penyu dapat dilihat pada tabel berikut.

Tabel 3: Jumlah Daya Dukung Kawasan Pantai Kampung Penyu

: Rekreasi Pantai/ Kawasan Eksisting

\begin{tabular}{c|c|c|c|c|c|c|}
\hline Lokasi & $\mathbf{K}$ (Orang) & $\mathbf{L p}\left(\mathbf{M}^{2}\right)$ & $\mathbf{L t}$ & $\mathbf{W p}$ & $\mathbf{W t}$ & $\begin{array}{c}\text { DDK } \\
\text { (Org/Hari) }\end{array}$ \\
\hline Lokasi 1 & 1 & $22.228,27$ & $50 \mathrm{~m}^{2}$ & 6 & 3 & 889 \\
\hline Lokasi 2 & 1 & $20,394,95$ & $50 \mathrm{~m}^{2}$ & 6 & 3 & 816 \\
\hline Lokasi 3 & 1 & $8.781,44$ & $50 \mathrm{~m}^{2}$ & 6 & 3 & 351 \\
\hline
\end{tabular}

Sumber: Hasil Analisis 2019

Tabel 4: Jumlah Daya Dukung Kawasan Pantai Kampung Penyu 
: Berenang dan Berjemur / Area Berenang

\begin{tabular}{ccrcccc}
\hline Lokasi & $\mathrm{K}$ (Orang) & \multicolumn{1}{c}{$\mathrm{Lp}\left(\mathrm{M}^{2}\right)$} & $\mathrm{Lt}$ & $\mathrm{Wp}$ & $\mathrm{Wt}$ & $\mathrm{DDK}($ Orang/Hari) \\
\hline Lokasi 1 & 1 & $54.918,32$ & $50 \mathrm{~m}^{2}$ & 8 & 2 & 3.295 \\
Lokasi 2 & 1 & $65.282,4$ & $50 \mathrm{~m}^{2}$ & 8 & 2 & 3.391 \\
Lokasi 3 & 1 & $59.023,82$ & $50 \mathrm{~m}^{2}$ & 8 & 2 & 3.541 \\
\hline
\end{tabular}

Sumber : Hasil Analisis 2019

Tabel 5: Jumlah Daya Dukung Kawasan Pantai Kampung Penyu

: Olahraga Pantai / Sepanjang Garis Pantai

\begin{tabular}{ccccccc}
\hline Lokasi & $\mathrm{K}$ (Orang) & $\mathrm{Lp}\left(\mathrm{M}^{2}\right)$ & $\mathrm{Lt}$ & $\mathrm{Wp}$ & $\mathrm{Wt}$ & $\mathrm{DDK}($ Orang/Hari) \\
\hline Lokasi 1 & 1 & $16.652,87$ & $50 \mathrm{~m}^{2}$ & 6 & 2 & 999 \\
Lokasi 2 & 1 & 15.520 .04 & $50 \mathrm{~m}^{2}$ & 6 & 2 & 931 \\
Lokasi 3 & 1 & $8.781,44$ & $50 \mathrm{~m}^{2}$ & 6 & 2 & 526 \\
\hline
\end{tabular}

Sumber : Hasil Analisis 2019

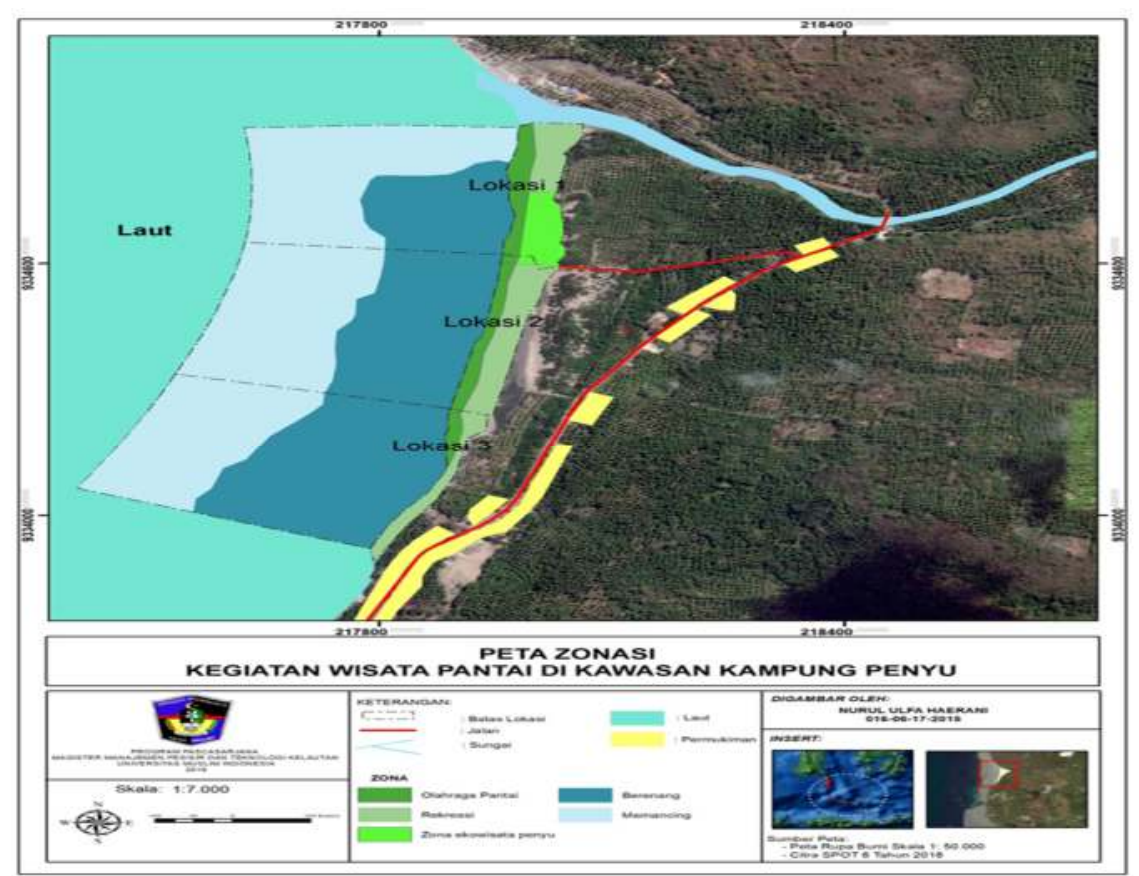

Gambar 4. Peta Zonasi Wisata Pantai

- Tujuan Responden Berkunjung ke Pemukiman Dusun Tulang dan sekitar \pm

Lokasi Wisata Pantai Kampung $12 \mathrm{Km}$ dari Kota Benteng sangat

Penyu

Kawasan konservasi penyu yang melintasi kawasan ini menuju pantai memiliki jarak $\pm 200 \mathrm{~m}$ dari wisata. Berdasarkan hasil akumulasi 
jawaban responden ada beberapa tujuan responden berkunjung ke kawasan pantai penyu ini yang disajikan dalam Gambar berikut ini :

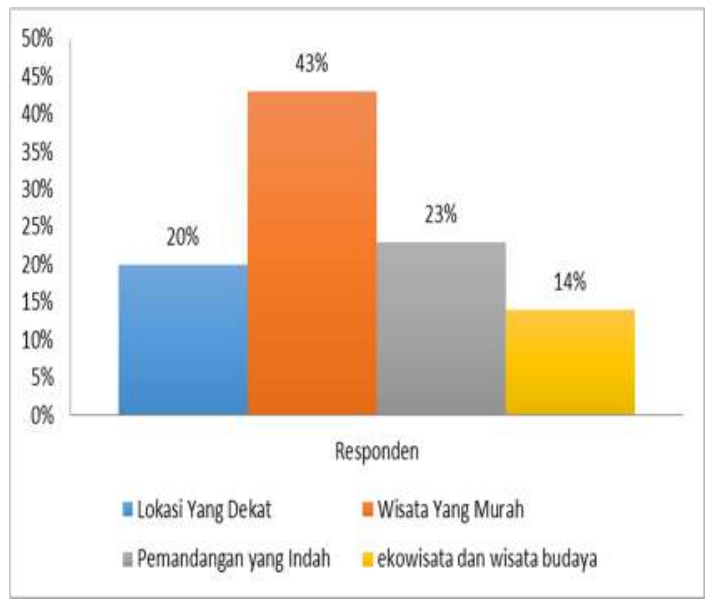

Gambar 5. Diagram Alasan Responden Berkunjung

\section{- Strategi Pengembangan Kawasan Konservasi Penyu Sebagai Kawasan Wisata Pantai}

Dari hasil perhitungan, posisi kuadran berada di Kuadran II yaitu penerapan strategi dengan melihat ancaman yang ada. Posisi ini menandakan Pantai Kawasan Kampung Penyu memiliki potensi untuk berkembang akan tetapi masih kurangnya pemahaman masyarakat akan pengembangan pariwisata dan menjaga kelesarian lingkungan. Rekomendasi strategi yang diberikan adalah Diversifikasi Strategi.

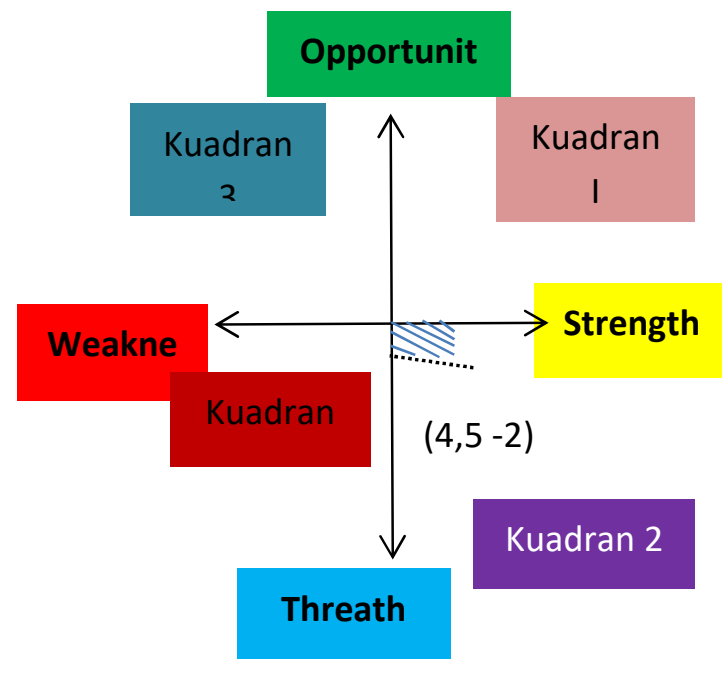

Gambar 6: Kuadran Matriks SWOT

Prioritas Strategi Pengembangan wisata pantai berdasrkan hasil diagram Kuadran pengembangan wisata pantai di Kawasan Kampung Penyu di Dusun Tulang Desa Barugaiya Kabupaten Kepulauan Selayar antara lain sebagai berikut:

- Meningkatkan kesadaran dan kepedulian masyarakat dalam pengelolaan pariwisata melalui sosialisasi FGD (Focus Group Discussion) artinya penyadaran masyarakat mengenai potensi dampak positif dan negative pengembangan pariwisata khususnya wisata pantai di wilayah mereka di Desa Barugaiya Kecamatan Bontomanai. untuk mengetahui presepsi masyarakat khususnya stakeholder baiknya menggunakan metode FGD atau Focus Group Discussion. 
- Penerapan Zona Pengembangan Wisata yang ada pada RIPPDA Kabupaten Selayar dalam hal ini pemerintah sebagai pelaksana kebijakan perlu melakukan sosialisasi tingkat basis mengenai perencanaanperencanaan yang dibuat dan disosialisasikan ke masyarakat mengenai Zona Pengembangan Wisata dan Konservasi kepada masyarakat.

- Penerapan aturan dan kearifan local dalam menjaga lingkungan seperti menggerakkan masyarakat komunitas pesisir. pengembangan wisata pantai di Kawasan Kampung Penyu memiliki modal alam yang harus di jaga, keunikan dan budaya menjadi hal penting dalam pengembangan kawasan wisata.

\section{KESIMPULAN}

Berdasarkan hasil penelitian yang telah dilakukan di Wilayah Pesisir Dusun Tulang Desa Barugaiya Kabupaten Kepulauan Selayar maka dapat disimpulkan sebagi berikut:

1. Hasil analisis Potensi Wisata Pantai di Kawasan Kampung Penyu Dusun Tulang Desa Barugaiya Kabupaten Kepulauan Selayar memiliki potensi yang tinggi, dengan kegiatan wisata pantai seperti berenang, olahraga pantai, rekreasi (camping), ekowisata dan wisata budaya.

2. Hasil analisis Prioritas Strategi Pengembangan wisata pantai berdasarkan hasil analisis yang dilakukan ada 3 (tiga) hal yang menjadi keputusan taktis untuk rekomendasi dalam upaya pengelolaan kawasan konservasi penyu dan pengembangan kawasan ekowisata penyu, yaitu; (1) Meningkatkan kesadaran dan kepedulian masyarakat dalam pengelolaan pariwisata melalui sosialisasi FGD (Focus Group Discussion) (2) Penerapan Zona Pengembangan Wisata yang ada pada RIPPDA Kabupaten Selayar (3) Penerapan aturan dan kearifan lokal dalam menjaga lingkungan seperti menggerakkan masyarakat komunitas pesisir.

\section{SARAN}

1. Untuk Pihak pemerintah Kabupaten Kepulauan Salayar sebaiknya melakukan Inovasi di Bidang Pariwisata seperti Tour de Tourism di Kabupaten Kepulauan Selayar yang memiliki banyak objek wisata pantai an

$$
\text { wisata }
$$

Bahari. 
2. Pemerintah perlu melakukan pembangunan sarana dan prasarana penunjang untuk menarik wisatawan berlibur Ke Kabupaten Kepulauan Selayar.

3. Perlunya pemerintah Kabupaten Kepulauan Selayar menyediakan Website Pariwisata guna masyarakat dapat mengakses lokasi-lokasi wisata yang patut dikunjungi jika berkunjung ke Pulau Selayar

\section{UCAPAN TERIMA KASIH}

Tulisan ini merupakan bagian dari penelitian Tesis dan penulis mengucapkan terima kasih kepada Ketua Prodi Manajemen Pesisir dan Teknologi Kelautan dan Direktur Pasca Sarjana yang telah memberi kesempatan untuk melanjutkan pendidikan di PPS UMI.

\section{DAFTAR PUSTAKA}

Amdani,. Suut. 2008. Analisis potensi obyek wisata alam pantai Di Kabupaten Gunung Kidul (Skripsi).

http://eprints.ums.ac.id/967/1/E1 00020020.pdf. Diakses( 19 Maret 2018).

Dinas Kebudayaan dan Pariwisata [DISBUDPAR] Kabupaten Kepulauan Selayar. 2017. Rencana Induk Pengembangan Pariwisata Kabupaten layar Tahun 2017-2022.
Nugroho. Iwan. 2011. Ekowisata dan Pembangunan Berkelanjutan. Malang. Pustaka Belajar.

Keraf. A. Sony. 2002. Etika Lingkungan Hidup. Jakarta. Kompas.

Masita H.K, Femy M.S, Sri N.H,. 2013. ( Jurnal) Kesesuaian Wisata Pantai Berpasir Pulau Saronde Kecamatan Pondo Kepulauan Kabupaten Gorontalo Utara.

Senoaji, G. 2009. Daya dukung lingkungan dan kesesuaian lahan dalam pengembangan Pulau Enggano Bengkulu. Jurnal Bumi Lestari. 9 (2) : 159-166.

Umar, Muhammad Zulkarnain. 2013. Strategi Untuk Mengembangkan Pantai Sebanjar Sebagai Objek Pariwisata Unggulan di Kabupaten Alor Propinsi NTT. Tugas Akhir. Program Studi Perencanaan Wilayah dan Kota, Fakultas Teknik, Universitas Islam Bandung.

Yoeti, O.A, 1996. Pengantar Ilmu Pariwisata, Bandung: Angkasa

Yulianda, F. 2007. Ekowisata bahari sebagai alternatif pemanfaatan sumberdaya pesisir berbasis konservasi. Institut Pertanian Bogor. Bogor.

Yulisa. Eka Noerma, dkk. Analisis Kesesuaian Dan Daya Dukung Ekowisata Pantai Kategori Rekreasi Pantai Laguna Desa Merpas Kabupaten Kaur. Jurnal Enggano Vol. 1. http//www.researchgate.net/profil e/Yar Johan (Diakses 20 Maret 2018). 
Wabang. Manuel Lamma, dkk. Kajian Karakteristik Tipologi Pantai untuk pengembangan Wisata Rekreasi Pantai Di Suka Alam Perairan Selat Pantar Kabupaten Alor. Volume I, No 2, Juni 2017 Hal 199-209. http://journal.ipb.ac.id/index.php/ pspalbacore/article/viewFile/181 72/12965. (Diakses 20 Maret 2018).

Andi Panca Wahyuni1, Yonvitner, dan Isdradjad Setyobudiandi2. (Jurnal:2017) Daya Dukung Kawasan Pantai Timur Kabupaten Bulukumba Untuk Aktivitas Wisata Bahari.

Agustiningsih, Siswoyo, Tridiana. (Jurnal). Analisis S.W.O.T Untuk Perencanaan Dan Pengembangan Ekowisata Pantai Pasir Putih Kabupaten Situbondo www.academia.edu/.../Analisis S .W.O.T untuk Perencanaan dan ...(Diakses. 17 Februari 2019).

Amdani, Suut. (Skripsi: 2008). Analisis Potensi Obyek Wisata Alam Pantai Di Kbupaten Gunung Kidul.

eprints.ums.ac.id/967/1/E100020 020.pdf. (Diakses: 16 September 2018).
Arif , Muhammad. Alexander Syam. (Jurnal: 2017) Strategi Pengembangan Objek Wisata Pantai Sumedang di Kecamatan Ranah Pesisir Kabupaten Pesisir Selatan. https:/lejurnal.stkippessel.ac.id/index.php/kp/article/. ../161/106. (Diakses. 17 Februari 2019).

Marjoko (Skripsi: 2008) Analisis Potensi Dan Pengembangan Objek Wisata Air Umbul Ingas Di Kecamatan Tulung Kabupaten Klaten Tahun 2008. https://digilib.uns.ac.id/...=/Anali sis-potensi-dan-pengembanganOb... (Diakses: 20 September 2018)

Fahrina, Ayuliya. (2011). Penataan Kawasan Obyek Wisata Pantai Baloiya Kecamatan Bontosikuyu Kabupaten Kepulauan Selayar. repositori.uinalauddin.ac.id/6369/1/Ayuliya\%2 OFahrina.pdf. (Diakses: 28 Oktober 2018).

Fama, Achmad. Haeruddin2, dan Frida Purwant (Jurnal: 2017) Kesesuaian Dan Daya Dukung Pemanfaatan Pantai Kartini Jepara Sebagai Destinasi Wisata 